\title{
(S)-[6]-Gingerol enhances glucose uptake in L6 myotubes by activation of AMPK in response to $\left[\mathrm{Ca}^{2+}\right]_{i}$
}

\author{
Yiming Li, Van H Tran, Nooshin Koolaji, Colin C Duke, Basil D Roufogalis \\ Faculty of Pharmacy, The University of Sydney, NSW 2006, Australia
}

Received, June 18, 2013; Accepted, June 30, 2013; Published, July 4, 2013

\begin{abstract}
PURPOSE. The aim of this study was to investigate the mechanism of $(S)$-[6]-gingerol in promoting glucose uptake in L6 skeletal muscle cells. METHODS. The effect of $(S)$-[6]-gingerol on glucose uptake in L6 myotubes was examined using 2-[1,2- $\left.{ }^{3} \mathrm{H}\right]$-deoxy-D-glucose. Intracellular $\mathrm{Ca}^{2+}$ concentration was measured using Fluo-4. Phosphorylation of AMPK $\alpha$ was determined by Western blotting analysis. RESULTS. (S)-[6]-Gingerol time-dependently enhanced glucose uptake in L6 myotubes. (S)-[6]-Gingerol elevated intracellular $\mathrm{Ca}^{2+}$ concentration and subsequently induced a dose- and time-dependent enhancement of threonine172 phosphorylated AMPK $\alpha$ in L6 myotubes via modulation by $\mathrm{Ca}^{2+} /$ calmodulin-dependent protein kinase kinase. CONCLUSION. The results indicated that (S)-[6]-gingerol increased glucose uptake in L6 skeletal muscle cells by activating AMPK. (S)-[6]-gingerol, a major component of Zingiber officinale, may have potential for development as an antidiabetic agent.

This article is open to POST-PUBLICATION REVIEW. Registered readers (see "For Readers") may comment by clicking on ABSTRACT on the issue's contents page.
\end{abstract}

\section{INTRODUCTION}

High calorie intake and low physical activity has led to a dramatic increase in the incidence of type 2 diabetes and in particular hyperglycemia and its complications over the past few decades. A number of intracellular signalling pathways are associated with regulation of blood glucose and may be targets of drug action. AMP-activated protein kinase (AMPK) has a key role in regulating energy fuel, as demonstrated at both the cellular and whole body level $(1,2)$. AMPK is a heterotrimeric complex comprised of one catalytic subunit $(\alpha)$ and two regulatory subunits ( $\beta$ and $\gamma$ ). Activation of AMPK occurs by phosphorylation at threonine 172 (Thr172) on the loop of the catalytic domain of the $\alpha$-subunit $(3,4)$. Currently, two major upstream kinases have been identified, the LKB1/STRAD/MO25 complex, which maintains the basal level of phosphorylation of AMPK $\alpha^{\text {Thr172, }}$ and the $\mathrm{Ca}^{2+} /$ calmodulin-dependent protein kinase kinase (CAMKK), which is triggered by increased intracellular $\mathrm{Ca}^{2+}$ concentration (5-7).

In skeletal muscle AMPK activation in response to metabolic stress leads to a switch of cellular metabolism from anabolic to catabolic states. Studies with AMP-mimetic compound 5 aminoimidazole -4 - carboxamide $-1-\beta-\mathrm{D}$ ribofuranoside (AICAR) showed that acute activation of AMPK increased glucose uptake by promoting glucose transporter (GLUT4) translocation to the plasma membrane as well as facilitated fatty acid influx and $\beta$-oxidation (8-10). Repetitive AMPK activation results in upregulation of numerous genes and proteins involved in energy metabolism.

(S)-[6]-Gingerol ( ( S ) - 5 - hydroxyl - 1 - [ 4' - hydroxyl-3'-methoxypheny 1]-3 - decanone) is the major pungent phenolic component in ginger (Zingiber officinale Roscoe, Family Zingiberaceae). Recent studies have shown that $(S)$-[6]-gingerol reduced blood glucose levels in diabetic animal models and promoted glucose uptake in in vitro cell-based experiments (11-14). However there are limited studies elucidating the molecular mechanisms associated with the action of (S)-[6]-gingerol. The present study aimed to investigate the effect of $(S)$-[6]-gingerol on glucose uptake in L6 skeletal muscle cells, and to investigate its potential to mediate AMPK activation and the role of the intracellular $\mathrm{Ca}^{2+}$ signal in this action.

Corresponding Author: Dr Colin Duke; Faculty of Pharmacy, The University of Sydney; NSW, Australia; Email: colin.duke@sydney.edu.au 


\section{MATERIALS AND METHODS}

\section{Materials}

L6 rat myoblast culture was purchased from European Collection of Cell Cultures (ECACC Salisbury, UK). Fluo-4 NW Calcium Assay Kit and Lipofectamine 2000 were purchased from Invitrogen (Mulgrave, Vic Australia). The AMPK and ACC Antibody Sampler Kit (\# 9957) and LumiGLO $^{\circledR}$ and Phototope ${ }^{\circledR}$-HRP detection reagent were obtained from Cell signaling (Arundel, Queensland Australia). 2-Deoxy-Dglucose (Grade III) and predesigned sets of duplexed siRNA were purchased from SigmaAldrich (Castle Hill, NSW Australia). 2-[1,2- $\left.{ }^{3} \mathrm{H}\right]-$ Deoxy-D-glucose was purchased from PerkinElmer (Massachusetts, USA).

\section{Preparation of $(S)$-[6]-gingerol}

(S)-[6]-Gingerol ((S)-5-Hydroxy-1-[4'-hydroxy-3'methoxyphenyl]-3-decanone) was isolated from total ginger extract as described previously (14). Briefly, freeze dried powder of ginger rhizome (1 Kg) (Grade A, batch No. 9240089, provided by Buderim Ginger Limited, Queensland, Australia) was extracted with ethyl acetate (3 L) with stirring at room temperature. The filtrate was collected and evaporated under reduced pressure to afford a liquid residue $(55 \mathrm{~g})$ as total ginger extract. (S)-[6]Gingerol (purity of $94.0 \%$ ) was obtained by further purification using a normal phase short column vacuum chromatography (NP-SCVC) system (14).

\section{Cell culture}

L6 myoblasts were maintained in $\alpha$-minimal essential medium with $10 \%$ fetal bovine serum (FBS) at $37^{\circ} \mathrm{C}$ in an atmosphere of $5 \% \mathrm{CO}_{2}$. When myoblasts grew to confluence, cells were allowed to fuse into multinucleated myotubes in $\alpha$-MEM containing $2 \%$ heat-treated newborn calf serum (CS).

\section{Glucose uptake assay}

L6 myoblasts were seeded in 48-well plates at a density of $4 \times 10^{4}$ cells $/ \mathrm{cm}^{2}$ and allowed to fuse into myotubes as described above. The assays were performed when over $70 \%$ myotubes had formed. On the day of testing, the cells were washed twice with phosphate-buffered saline solution (PBS), and starved in serum-free $\alpha$-MEM in $0.5 \%(\mathrm{w} / \mathrm{v})$ bovine serum albumin containing treatment samples for 5 hours, followed by a quick wash with Krebs-Ringer-phosphate-Hepes buffer (KRPH, 20

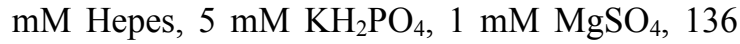
$\mathrm{mM} \mathrm{NaCl}, 4.7 \mathrm{mM} \mathrm{KCl}, 1 \mathrm{mM} \mathrm{CaCl}_{2}, \mathrm{pH}$ 7.4).
Test samples were incubated for the indicated time periods. Where inhibitors were used, cells were pre-treated for 30 minutes before adding treatment compounds. The cells were then incubated in $\mathrm{KRPH}$ and 2- deoxy-glucose uptake was measured over a 5 minute period $(100 \mu \mathrm{M}$ 2-deoxy-Dglucose with $2-\left[1,2-{ }^{3} \mathrm{H}\right]$-deoxy-D-glucose 0.3 $\mu \mathrm{Ci} /$ well $)$ at room temperature $\left(20-25^{\circ} \mathrm{C}\right)$. The uptake was terminated by 5 quick washes with icecold PBS. The plates were air-dried for 15 minutes and cells were lysed in $0.05 \mathrm{~N} \mathrm{NaOH}$ solution. The radioactivity of $2-\left[1,2-{ }^{3} \mathrm{H}\right]$-deoxy-D-glucose in the cell lysate was determined in a scintillation counter.

\section{Intracellular $\mathrm{Ca}^{2+}$ concentration}

L6 myoblasts were seeded in 96-well black clear bottom plates and differentiated into myotubes as described above. The intracellular $\mathrm{Ca}^{2+}$ concentration was measured using Fluo-4 NW Calcium Assay Kit following the manufacturer's instruction. Briefly, on the day of experiment, the cells were washed twice with PBS, then $100 \mu$ l of Fluo-4 NW solution was added quickly to each well and incubated at $37^{\circ} \mathrm{C}$ for 30 minutes and left at room temperature for a further 30 minutes. Addition of treatment compounds was followed by immediate measurement of the fluorescence intensity of Fluo-4 at ex $485 \mathrm{~nm} / \mathrm{em} 520 \mathrm{~nm}$ by a real-time Novostar plate reader over 120 second time periods.

\section{Western blot analysis}

L6 myotubes were treated with $(S)$-[6]-gingerol for the indicated time periods. Where inhibitors were used, cells were pre-treated for 30 minutes before adding treatment compounds. Then the cells were washed twice with PBS, and lysed with RIPA buffer containing protease inhibitor and phosphatase inhibitor cocktail. The protein content of cell lysates was determined by Micro BCA ${ }^{\mathrm{TM}}$ protein assay kit. Thirty micrograms of protein was resolved on $4-12 \%$ SDS-PAGE, and then transferred to nitrocellulose membrane. The membrane was blocked with 5\% BSA/TBST for 1 hour, incubated with primary antibody overnight at $4^{\circ} \mathrm{C}$, then probed with goat anti-rabbit horseradish peroxidase-conjugated secondary antibody (1:5000, Cell Signaling) for 1 hour. Primary antibodies used were monoclonal rabbit antiphospho-AMPKa (Thr172) (1:2500, Cell Signaling), monoclonal rabbit anti-AMPK $\alpha$ (1:2500, Cell Signaling), polyclonal rabbit antiphospho-acetyl-CoA carboxylase (Ser79) (1:2500, Cell Signaling), and monoclonal rabbit anti-acetylCoA carboxylase (1:2500, Cell Signaling). Protein 
bands were detected with LumiGLO $^{\circledR}$ and Phototope ${ }^{\circledR}$-HRP detection reagent. The intensity of bands was determined using the ImageJ image processing program.

\section{AMPKa1/a2 siRNA knockdown}

AMPK $\alpha 1 / \alpha 2$ siRNA were transfected for 48 hours when $60-70 \%$ of L6 myoblasts were differentiated into myotubes. The siRNA sequence of SASI Rn01_ $00074869-$ AMPK $\alpha 1$ is 5'CCÜAUGAAGAGGGCCACAA3', SASI 00067553 - AMPK $\alpha 2$ is 5'CCUAUGAUGCUAACGUCAU3', and the positive control GAPDH is 5'CCUUCUCUCGAAUACCAU3'. The unrelated siRNA control was MISSION ${ }^{\circledR}$ Universal Negative Control (SIC001, Sigma-Aldrich). The transfection and knockdown efficiency of siRNA were determined 48 hours post transfection (data available on request). AMPK $\alpha 1 / \alpha 2$ protein expression and glucose uptake assays were performed after 48 hours of transfection.

\section{STATISTICS}

All data are presented as mean \pm SEM of three independent experiments. Results were analysed using one way analysis of variance (ANOVA) followed by the Newman-Keuls post hoc test. Differences were considered significant when $P$ values were less than $0.05(P<0.05)$.

\section{RESULTS}

\section{$(S)$-[6]-Gingerol enhances glucose uptake in L6} myotubes

The time dependent effect of $(S)$-[6]-gingerol on glucose uptake in L6 myotubes was examined. Glucose uptake was observed to increase from 1 to 24 hours in L6 myotubes treated with $(S)$-[6]gingerol $(150 \mu \mathrm{M})$. A significant increase was achieved within 1 hour of treatment (Figure 1).

\section{$(S)$-[6]-Gingerol enhances phosphorylated-} AMPK $\alpha$-subunit in L6 myotubes

Our previous study demonstrated that $(S)$-[6]gingerol enhanced glucose uptake in L6 myotubes (14). The involvement of AMPK and phosphorylated $\mathrm{AMPK} \alpha^{\text {Thr172 }}$ (p-AMPK $\alpha^{\text {Thr172 }}$ ) in $(S)$-[6]-gingerol stimulated glucose uptake were examined after $(S)$-[6]-gingerol $(150 \mu \mathrm{M})$ treatment by Western blot analysis. P-
$\mathrm{AMPK} \alpha^{\text {Thr172 }}$ was found to be elevated rapidly and reached a peak of 5.5-fold over basal level at 10 minutes, then declined gradually and was maintained at 3.5-fold thereafter (Figure 2A). Consistent with the increase of $\mathrm{p}$-AMPK $\alpha^{\text {Thr172 }}$, phosphorylated acetyl-CoA carboxylase (p$\mathrm{ACC}^{\text {Serine79}}$ ), one of the downstream targets of AMPK, was elevated maximally within 5 min and was maintained thereafter (Figure 2B).

\section{(S)-[6]-Gingerol -induced AMPK phosphorylation was mediated by CaMKK in L6 myotubes}

The $\mathrm{Ca}^{2+}$ signal is involved in a broad range of skeletal muscle activities. (S)-[6]-Gingerol increased intracellular $\mathrm{Ca}^{2+}$ concentration in a dosedependent manner within 1 minute in L6 myotubes (Figure 3). The increase appeared more gradual than the rapid increase seen with carbachol as a control, which indicated that (S)-[6]-gingerolinduced intracellular $\mathrm{Ca}^{2+}$ rise occurred through a mechanism distinct from that with carbachol.

P-AMPK $\alpha^{\text {Thr172 }}$ increased significantly in L6 myotubes treated with the calcium ionophore A23187 $(1 \mu \mathrm{M})$. AMPK activator AICAR $(1 \mathrm{mM})$ also increased the AMPK $\alpha^{\text {Thr172 }}$ phosphorylation level, and the activation by AICAR was blocked by the AMPK inhibitor Compound $\mathrm{C}$, which was consistent with a previous study (15). (S)-[6]Gingerol $(50,100$ and $150 \mu \mathrm{M})$ dose-dependently increased $\mathrm{AMPK \alpha}{ }^{\mathrm{Thr} 172}$ phosphorylation levels. Addition of the CaMKK inhibitor STO609 (16) $(2.67 \mu \mathrm{M}) 30$ minutes before $(S)$-[6]-gingerol (150 $\mu \mathrm{M})$ treatment, decreased $\mathrm{p}$-AMPK $\alpha^{\mathrm{Thr} 172}$ level drastically compared to that with $(S)$-[6]-gingerol alone (Figure 4). These results indicated that $(S)$ [6]-gingerol- induced AMPK $\alpha$ phosphorylation was modulated by raised intracellular $\mathrm{Ca}^{2+}$ and mediated via CaMKK.

We next investigated the role of $\mathrm{Ca}^{2+}$ and CaMKK activation in $(S)$-[6]-gingerol-stimulated glucose uptake. Pretreatment of L6 myotubes with the intracellular $\mathrm{Ca}^{2+}$ chelator BAPTA-AM abolished the stimulation of glucose uptake by $(S)$ [6]-gingerol. Glucose uptake was also abolished by pretreatment with the CaMKK inhibitor STO609 (Figure 5). The significant increment of glucose uptake by AICAR was diminished by adding its inhibitor Compound C. The calcium ionophore A23187 increased glucose uptake slightly (1.27fold), and it was decreased by adding calcium chelator BAPTA-AM. 


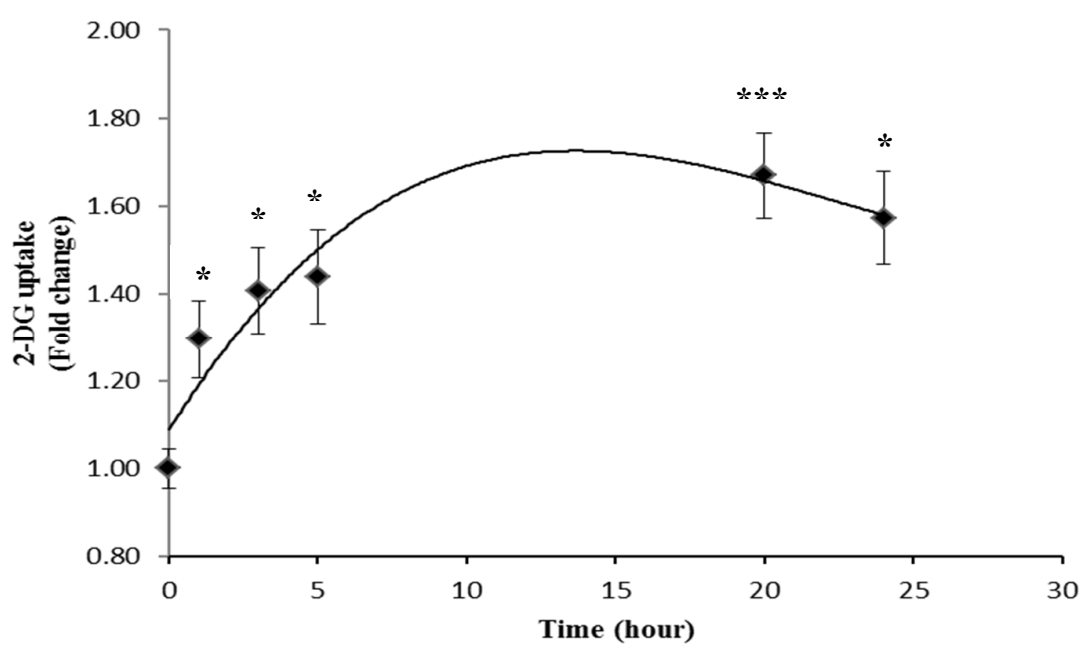

Figure 1. Effect of $(S)$-[6]-gingerol on glucose uptake in L6 myotubes. L6 myotubes were treated with $(S)$-[6]-gingerol $(150 \mu \mathrm{M})$ for 1, 3, 5, 20 and 24 hours, as described in Materials and Methods. 2-Deoxy-D-glucose (2-DG) uptake was measured over 5 minutes at room temperature. All data are presented as mean \pm SEM of 3 independent experiments performed in triplicate. $* P<0.05, * * * P<0.001 v s$. Control.

A

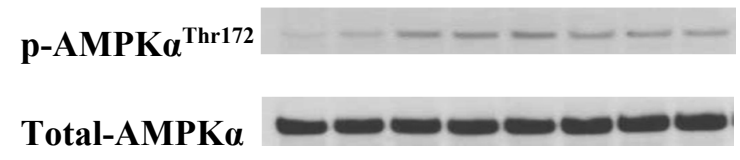

$\begin{array}{cccccccc}0 & 1 & 3 & 5 & 10 & 20 & 40 & 60 \\ \text { Time (minute) } & & & \end{array}$

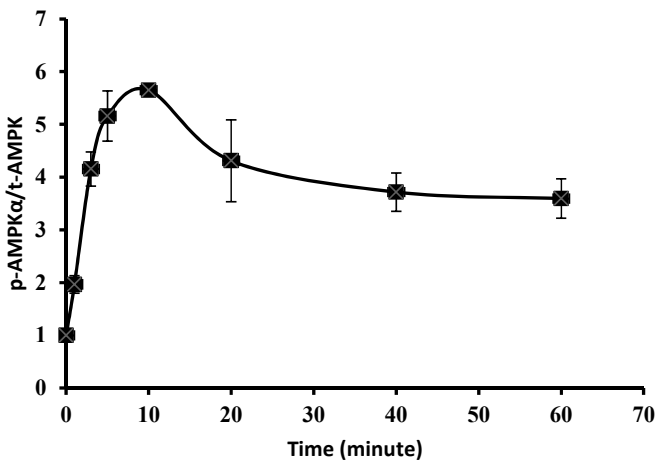

B
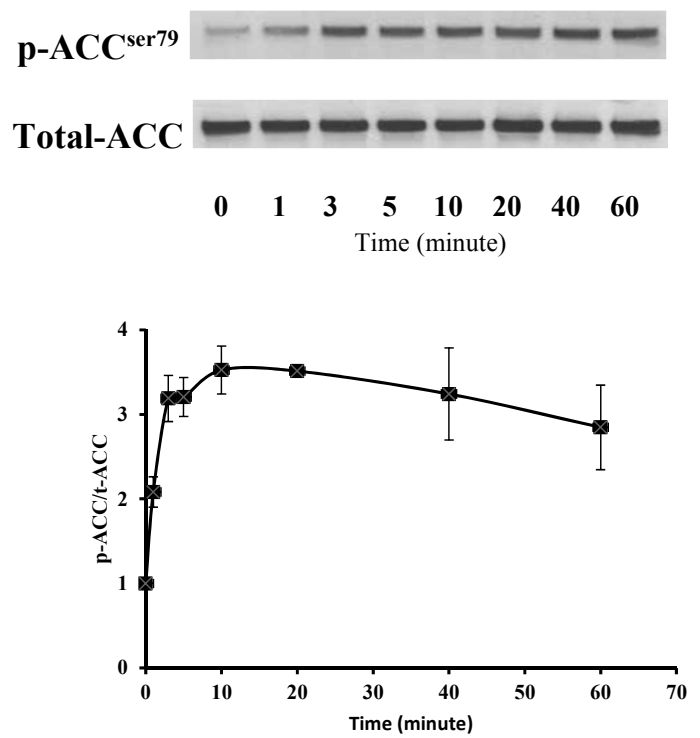

Figure 2. Time-dependent effect of $(S)$-[6]-gingerol on AMPK $\alpha^{\text {Thr172 }}$ and ACC ${ }^{\text {Ser79 }}$ phosphorylation in L6 myotubes. The levels of phosphorylated $\mathrm{AMPK} \alpha^{\mathrm{Thr} 172}(\mathrm{~A})$ and $\mathrm{ACC}^{\mathrm{Ser} 79}(\mathrm{~B})$ were analysed by Western blot at 1, 3, 5, 20, 40 and 60 minutes with $(S)$-[6]-gingerol $(150 \mu \mathrm{M})$ treatment. Data are from 3 independent experiments.

\section{Which AMPKa isoform is involved in glucose uptake?}

To determine which AMPKa isoform was dominant in mediating $(S)$-[6]-gingerol stimulated glucose uptake in L6 myotube, AMPK $\alpha 1$ or AMPK $\alpha 2$ was selectively knocked down by transfecting their corresponding siRNAs. The transfection efficiency was tested using a FAMconjugated MISSION $^{\circledR} \quad$ Universal Negative
Control, and achieved $80.43 \%$ knockdown of target gene using GAPDH positive control (data not shown but available as Supplementary information).

A significant reduction in protein expression was found to occur to a similar extent in both AMPK $\alpha 1$ and AMPK $\alpha 2$ knockdown L6 myotubes (Figure 6A and 6B). 


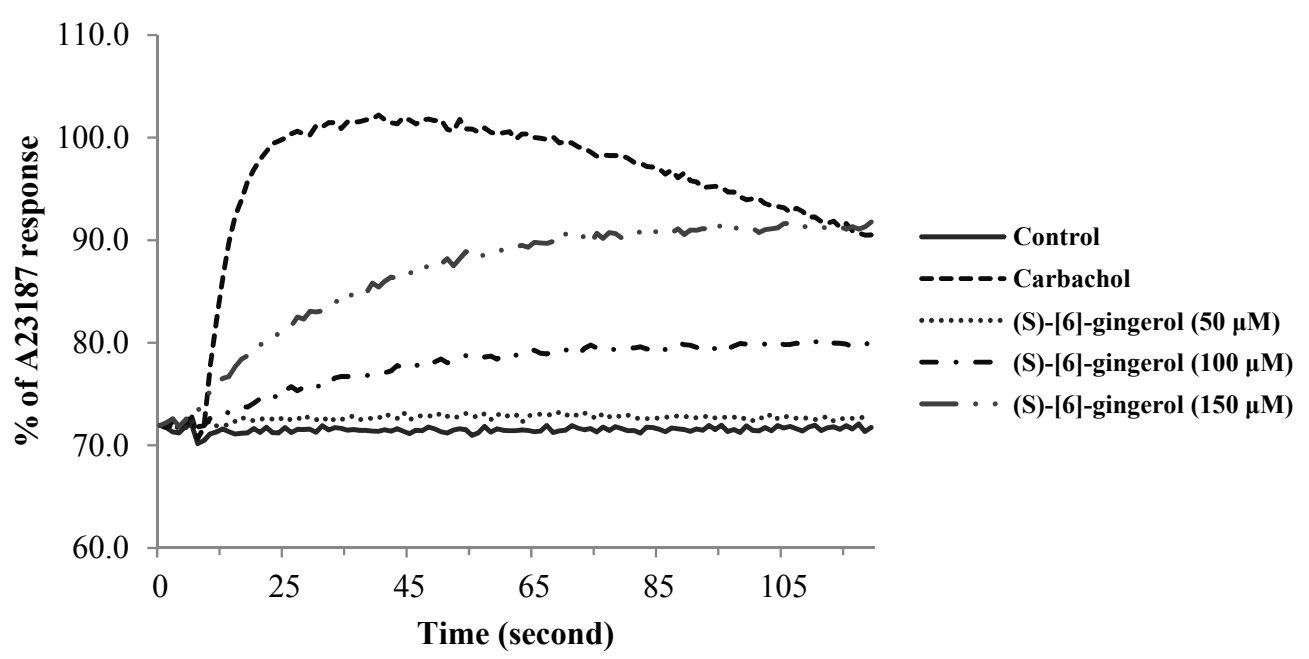

Figure 3. Effect of $(S)$-[6]-gingerol on $\left[\mathrm{Ca}^{2+}\right]_{i}$ in L6 myotubes. L6 myotubes were incubated with $(S)$-[6]-gingerol (50, 100 and $150 \mu \mathrm{M}) .\left[\mathrm{Ca}^{2+}\right]_{i}$ was measured using Fluo-4 NW as described in Materials and Methods. Data are presented as \% of maximum A23187 $(1 \mu \mathrm{M})$ response. Data are from 3 independent experiments.

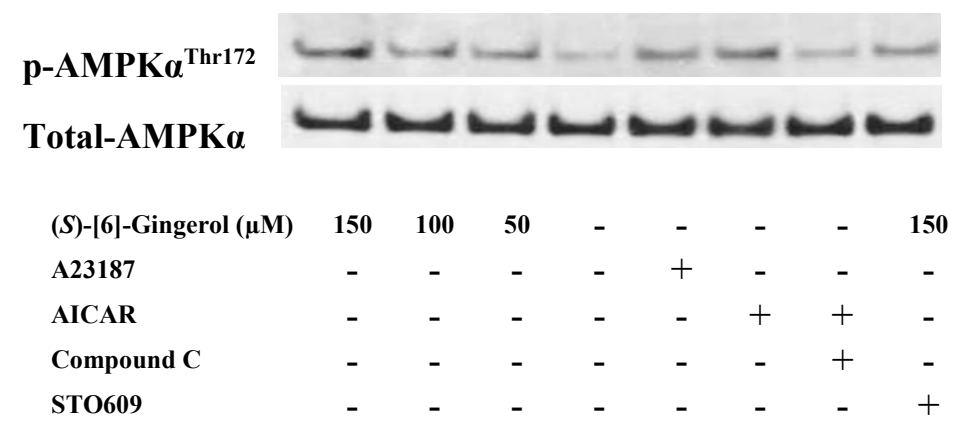

Figure 4. Effect of $(S)$-[6]-gingerol on AMPK $\alpha^{\text {Thr172 }}$ phosphorylation. AMPK $\alpha^{\text {Thr172 }}$ phosphorylation $\left(\mathrm{p}-\mathrm{AMPK} \alpha^{\mathrm{Thr} 172}\right)$ in L6 myotubes was detected following treatment with $(S)$-[6]-gingerol, A23187 $(1 \mu \mathrm{M})$ and AICAR $(1 \mathrm{mM})$ for 10 minutes. Inhibitors Compound C and STO609 were added 30 minutes prior to the treatments. The graph is the representative image of three independent experiments.

The $(S)$-[6]-gingerol stimulated glucose uptake was diminished in AMPK $\alpha 1$ and AMPK $\alpha 1 / \alpha 2$ knockdown L6 myotubes, whilst the increment of glucose uptake by (S)-[6]-gingerol was not affected in AMPK $\alpha 2$ knockdown cells (Figure 6C). This indicated that AMPK $\alpha 1$ was the dominant isoform involved in $(S)$-[6]-gingerol stimulated glucose uptake in L6 skeletal muscle cells.

\section{DISCUSSION}

The main finding of this study is that $(S)$-[6]gingerol increased glucose uptake in L6 skeletal muscle cells, and that the stimulation involves AMPK $\alpha$ activation. Though mounting evidence has suggested that ginger and its major chemical components were effective in alleviating hyperglycaemia and dyslipidaemia, the mechanisms underlying these actions remained largely unclear (16). To our knowledge this is the first study to reveal the role of AMPK in $(S)$-[6]gingerol stimulated glucose uptake. It has been well established that AMPK plays an important role in mediating energy homeostasis. Recent evidence showed that AMPK activation facilitated acute glucose uptake by triggering glucose transporter GLUT4 trafficking via phosphorylation of TBC1D1, a downstream protein shared in the insulin signalling transduction pathway $(17,18)$. AMPK activation also up- regulated the expression of peroxisome proliferator-activated receptor gamma coactivator 1-alpha (PGC-1 $\alpha)$, a transcriptional cofactor regulating mitochondrial biogenesis and GLUT4 expression (19-22). Therefore AMPK has been considered a potential 
target for developing therapeutic agents to treat type 2 diabetes (23).

In support of a role of AMPK in $(S)$-[6]gingerol stimulated glucose uptake we showed that the downstream target of AMPK, acetyl-CoA carboxylase (ACC), was also phosphorylated in $(S)$-[6]-gingerol treated L6 myotubes. ACC plays a key role in de novo fatty acid biosynthesis by catalysing carboxylation of acetyl-CoA to form malonyl-CoA. Accumulation of malonyl-CoA inhibits carnitine palmitoyltransferase 1 (CPT1) to transfer long-chain fatty acyl-CoA from cytosol into mitochondria for further oxidation (24). A decrease of malonyl-CoA was reported to diminish insulin resistance in fat-fed rats (25). Phosphorylation of $\operatorname{Ser}^{79}$ in ACC will subsequently inactivate the enzyme, leading to a switch of the cellular metabolism from energy storage to expenditure.

Calcium is a universal secondary messenger involved in a broad range of cell activities $(26,27)$. $(S)$-[6]-gingerol has been shown to evoke intracellular $\mathrm{Ca}^{2+}$ transients in dorsal root ganglion (DRG) neurones by activating vanilloid (TRPV1) receptor (28). (S)-[6]-Gingerol was also able to induce a significant rise of $\left[\mathrm{Ca}^{2+}\right]$ via stimulating extracellular $\mathrm{Ca}^{2+}$ influx and intracellular $\mathrm{Ca}^{2+}$ release in kidney cells (29). Our data showed that $(S)$-[6]-gingerol induced a gradual increase of intracellular $\mathrm{Ca}^{2+}$ concentration, but the molecular target of this action is as yet unidentified. The time course of $\left[\mathrm{Ca}^{2+}\right] i$ increase by $(S)$-[6]-gingerol was consistent with the time course for induction of $\mathrm{p}$ $\mathrm{AMPK} \alpha^{\mathrm{Thr} 172}$, which occurred rapidly and reached a peak at 10 minutes. To examine whether AMPKa $\alpha^{\text {Thr172 }}$ phosphorylation by $(S)$-[6]-gingerol was mediated by the CaMKK, a selective CaMKK inhibitor, STO609, was added to L6 skeletal muscle cells before treatment with $(S)$-[6]-gingerol. It was found that STO609 inhibited AMPKa $\alpha^{\text {Thr172 }}$ phosphorylation levels significantly compared to (S)-[6]-gingerol alone (Figure 4). In parallel, $(S)$ [6]-gingerol-stimulated glucose uptake was completely abolished by STO609 (Figure 5). These results suggested that the enhancement of glucose uptake by $(S)$-[6]-gingerol was mediated through the $\mathrm{Ca}^{2+} / \mathrm{CaMKK}$-AMPK pathway.

The glucose transporter GLUT4 is the principle isoform responsible for glucose clearance in peripheral tissues. Though the dynamic nature of GLUT4 has been extensively studied in the past few decades, the role of $\mathrm{Ca}^{2+}$ in mediating GLUT4 trafficking is not completely understood (30).

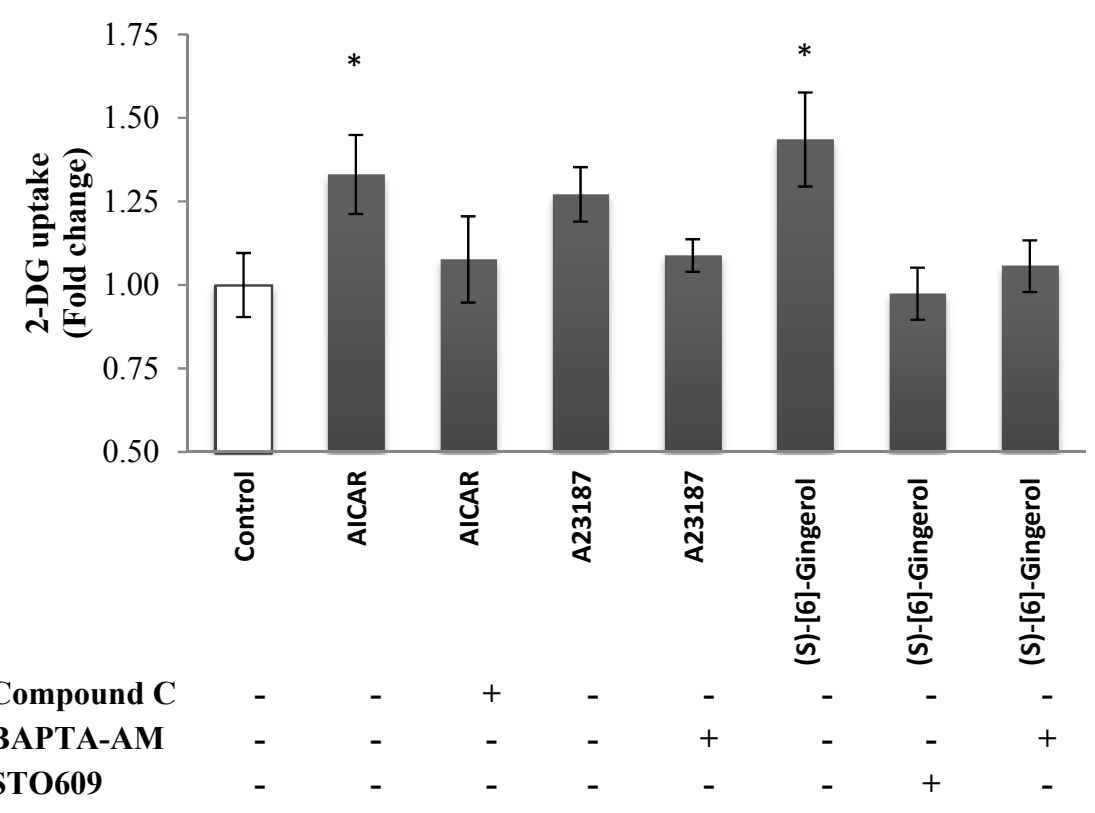

Figure 5. Mechanism of $(S)$-[6]-gingerol activation of glucose uptake in L6 myotubes. L6 myotubes were treated with $(S)$-[6]-gingerol $(150 \mu \mathrm{M})$, AICAR $(1 \mathrm{mM})$ or A23187 $(100 \mathrm{nM})$ for 1 hour, as described in Materials and Methods. Where BAPTA-AM $(10 \mu \mathrm{M})$, Compound C $(10 \mu \mathrm{M})$ or STO609 $(2.67 \mu \mathrm{M})$ were used, they were preincubated with L6 myotubes for 30 minute before treatments. 2-Deoxy-D-glucose (2-DG) uptake was measured over 5 minutes at room temperature. Data are the mean $\pm \mathrm{SEM}$ of 3 independent experiments performed in triplicate. ${ }^{*} P<0.05$ vs. Control. 
A

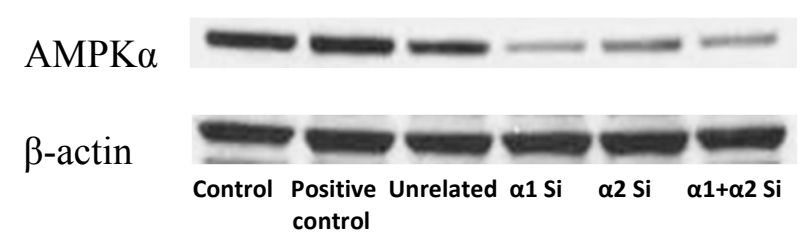

B

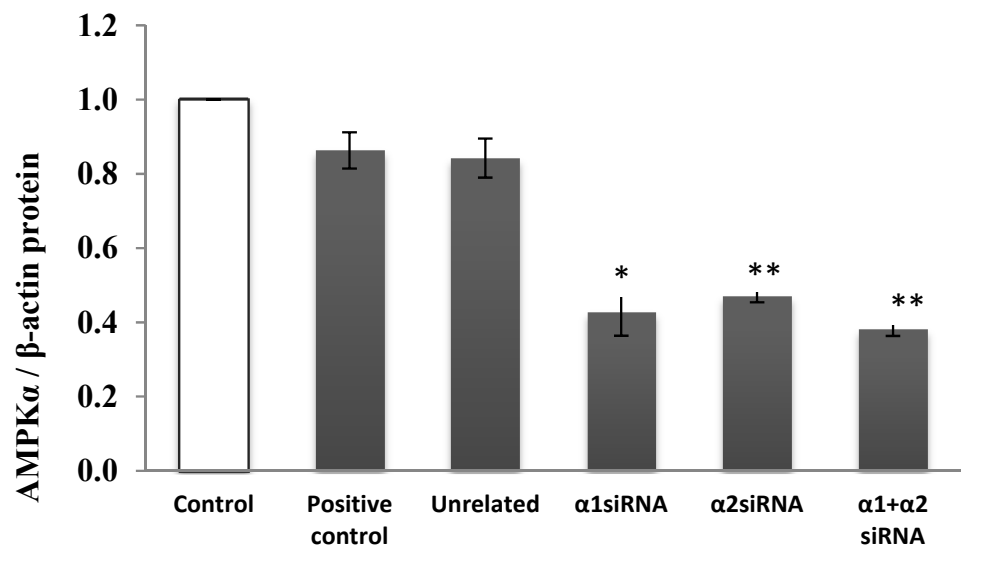

C

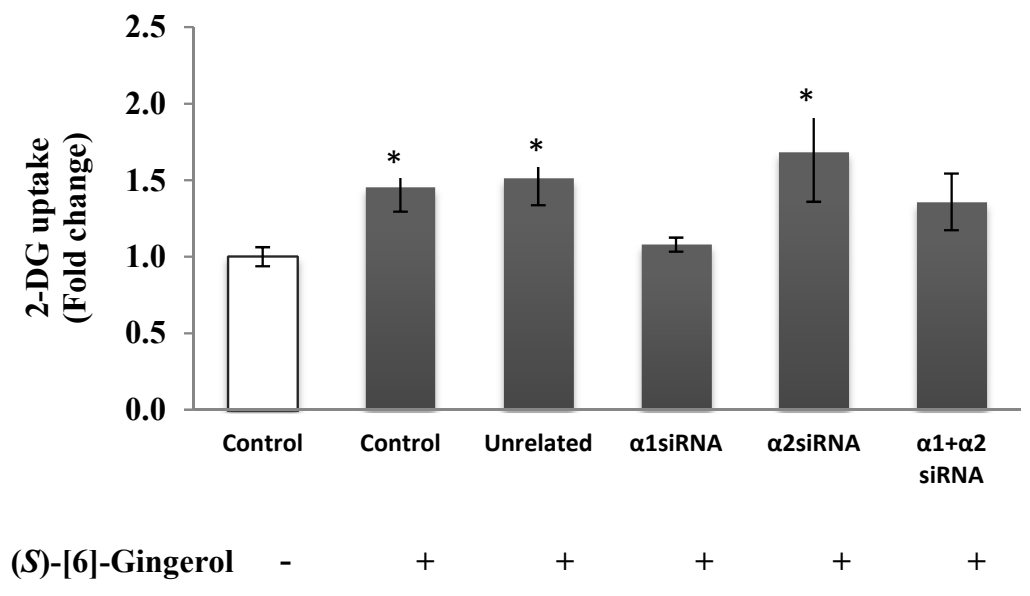

Figure 6. Effect of (S)-[6]-gingerol on glucose uptake on AMPK $\alpha 1$ and $\alpha 2$ knockdown in L6 myotubes A. Representative immunoblots of AMPK $\alpha 1$ and $\alpha 2$ expression after 48 hours transfection of siRNA . B. AMPK $\alpha 1$ and AMPK $\alpha 2$ protein expression. C. Effect of $(S)$-[6]-gingerol $(150 \mu \mathrm{M})$ on glucose uptake in AMPKa1 or $\alpha 2$ knockdown L6 myotubes. L6 myotubes were treated with (S)-[6]-gingerol for 1 hour, as described in Materials and Methods. 2Deoxy-D-glucose (2-DG) uptake was measured over 5 minutes at room temperature. Data are the mean \pm SEM of 3 independent experiments performed in triplicate. ${ }^{*} P<0.05,{ }^{*} P<0.01 v s$. Control.

Recent studies supported the $\mathrm{Ca}^{2+}$ requirement for GLUT4 trafficking along the cortical actin filaments and fusion into the plasma membrane (31-33). Our previous study showed that $(S)$-[8]gingerol, a more potent homologue of $(S)$-[6]gingerol, enhanced glucose uptake either in the presence or absence of insulin by promoting GLUT4 translocation and fusion into plasma membrane (14). In this study the intracellular $\mathrm{Ca}^{2+}$ chelator BAPTA-AM completely abolished the effect of $(S)$-[6]-gingerol on glucose uptake in L6 myotubes, suggesting a pivotal role of $\mathrm{Ca}^{2+}$ in GLUT4 dynamics. The same result was observed in 3T3-L1 adipocytes in a previous study (34).

AMPK is highly expressed in skeletal muscle tissue (35). The two isoforms of the catalytic subunit AMPK $\alpha 1$ and AMPK $\alpha 2$ are encoded by distinct genes (36). It has been suggested that AMPK $\alpha 1$ and AMPK $\alpha 2$ have different physiological roles in mediating energy homeostasis. AMPK $\alpha 2$ tends to be more sensitive to cellular AMP variation (37). The results from 
isoform knockout rodent models demonstrated that AMPK $\alpha 2$ knockout mice were resistant to AICAR stimulated glucose uptake and presented insulin resistance $(38,39)$. However, it was found that in obese subjects, the basal AMPK $\alpha 1$ activity was reduced significantly compared to lean control, whilst AMPK $\alpha 2$ activity remained at the same level (40). In AMPKal knockout mice, low intensity contraction- stimulated glucose uptake in skeletal muscle was markedly decreased, but this was not the case in AMPK $\alpha 2$ knockout mice. A recent study showed that caffeine increased AMPK $\alpha 1$ activity and glucose uptake in rat epitrochlearis muscle without affecting energy status (41). In the present study, it was found that the (S)-[6]-gingerol stimulated increase of glucose uptake was completely abolished in AMPK $\alpha 1$ knockdown L6 myotubes, which indicated that $(S)$ [6]-gingerol increased glucose uptake preferentially via activation of the AMPK $\alpha 1$, rather than the AMPK $\alpha 2$ isoform.

\section{CONCLUSION}

The present study showed a significant and rapid increase of glucose uptake in (S)-[6]-gingerol treated L6 myotubes. This action of $(S)$-[6]gingerol was associated with an elevation of cytosolic $\mathrm{Ca}^{2+}$ concentration and enhancement of levels of phosphorylated $\mathrm{AMPK} \alpha^{\mathrm{Thr} 172}$, preferentially through the AMPK $\alpha 1$ isoform. Our data supports $(S)$-[6]-gingerol, the major pungent component of ginger (Zingiber officinale), as a candidate potential hypoglycaemic agent at least in part through its effectiveness in promoting glucose uptake in skeletal muscle.

\section{ACKNOWLEDGMENT}

This work was supported by an Australian Research Council Linkage grant (LP0989786).

\section{REFERENCES}

1. Lage R, Dieguez C, Vidal-Puig A, Lopez M. AMPK: a metabolic gauge regulating whole-body energy homeostasis. Trends in Molecular Medicine. 2008; 12: 539-549.

2. Witczak CA, Sharoff CG, Goodyear LJ. AMPactivated protein kinase in skeletal muscle: From structure and localization to its role as a master regulator of cellular metabolism. Cellular and Molecular Life Sciences. 2008; 23: 3737-3755.

3. Hawley SA, Davison M, Woods A, Davies SP, Beri RK, Carling D, Hardie DG. Characterization of the AMP-activated protein kinase kinase from rat liver and identification of threonine 172 as the major site at which it phosphorylates AMP-activated protein kinase. The Journal of biological chemistry. 1996; 44: 27879-27887.

4. Stein SC, Woods A, Jones NA, Davison MD, Carling D. The regulation of AMP-activated protein kinase by phosphorylation. Biochem J. 2000; 437-443.

5. Hawley SA, Selbert MA, Goldstein EG, Edelman AM, Carling D, Hardie DG. 5'-AMP activates the AMP-activated protein kinase cascade, and $\mathrm{Ca} 2+/$ calmodulin activates the calmodulindependent protein kinase I cascade, via three independent mechanisms. J Biol Chem. 1995; 45: 27186-27191.

6. Woods A, Johnstone SR, Dickerson K, Leiper FC, Fryer LG, Neumann D, Schlattner U, Wallimann T, Carlson M, Carling D. LKB1 is the upstream kinase in the AMP-activated protein kinase cascade. Curr Biol. 2003; 22: 2004-2008.

7. Momcilovic M, Hong SP, Carlson M. Mammalian TAK1 activates Snf1 protein kinase in yeast and phosphorylates AMP-activated protein kinase in vitro. J Biol Chem. 2006; 35: 25336-25343.

8. Merrill GF, Kurth EJ, Rasmussen BB, Winder WW. Influence of malonyl-CoA and palmitate concentration on rate of palmitate oxidation in rat muscle. J Appl Physiol. 1998; 5: 1909-1914.

9. Merrill GF, Kurth EJ, Hardie DG, Winder WW. AICA riboside increases AMP-activated protein kinase, fatty acid oxidation, and glucose uptake in rat muscle. Am J Physiol. 1997; 6 Pt 1: E1107-1112.

10. Kurth-Kraczek EJ, Hirshman MF, Goodyear LJ, Winder WW. 5' AMP-activated protein kinase activation causes GLUT4 translocation in skeletal muscle. Diabetes. 1999; 8: 1667-1671.

11. Nammi S, Sreemantula S, Roufogalis BD. Protective effects of ethanolic extract of Zingiber officinale rhizome on the development of metabolic syndrome in high-fat diet-fed rats. Basic \& clinical pharmacology \& toxicology. 2009; 5: 366-373.

12. Sekiya K, Ohtani A, Kusano S. Enhancement of insulin sensitivity in adipocytes by ginger. Biofactors. 2004; 1-4: 153-156.

13. Noipha K, Ratanachaiyavong S, Ninla-Aesong P. Enhancement of glucose transport by selected plant foods in muscle cell line L6. Diabetes Res Clin Pract. 2010; 2: e22-26.

14. Li Y, Tran VH, Duke CC, Roufogalis BD. Gingerols of Zingiber officinale enhance glucose uptake by increasing cell surface GLUT4 in cultured L6 myotubes. Planta Med. 2012; 14: 15491555 .

15. Hutchinson DC, Bentgsson T. AMP-activated protein kinase activation by adrenoceptors in L6 skeletal muscle cells: mediation by alpha1adrenoceptors causing glucose uptake. Diabetes. 2006; 55: 682-690.

16. Tokumitsu $H$, Inuzuka $H$, Ishikawa $Y$, Ikeda $M$, Saji I, Kobayashi R. STO-609, a specific inhibitor 
of the $\mathrm{Ca}(2+) /$ calmodulin-dependent protein kinase kinase. J Biol Chem. 2002; 18: 15813-15818

17. Pehmoller C, Treebak JT, Birk JB, Chen S, Mackintosh C, Hardie DG, Richter EA, Wojtaszewski JF. Genetic disruption of AMPK signaling abolishes both contraction- and insulinstimulated TBC1D1 phosphorylation and 14-3-3 binding in mouse skeletal muscle. Am J Physiol Endocrinol Metab. 2009; 3: E665-675.

18. Chen S, Murphy J, Toth R, Campbell DG, Morrice NA, Mackintosh C. Complementary regulation of TBC1D1 and AS160 by growth factors, insulin and AMPK activators. Biochem J. 2008; 2: 449-459.

19. Kahn BB, Alquier T, Carling D, Hardie DG. AMPactivated protein kinase: ancient energy gauge provides clues to modern understanding of metabolism. Cell metabolism. 2005; 1: 15-25.

20. Liang H, Ward WF. PGC-1alpha: a key regulator of energy metabolism. Adv Physiol Educ. 2006; 4: 145-151.

21. Hardie DG. AMP-activated protein kinase: a cellular energy sensor with a key role in metabolic disorders and in cancer. Biochem Soc Trans. 2011; 1: $1-13$.

22. $\mathrm{Wu} \mathrm{Z}$, Puigserver $\mathrm{P}$, Andersson U, Zhang C, Adelmant G, Mootha V, Troy A, Cinti S, Lowell B, Scarpulla RC, Spiegelman BM. Mechanisms controlling mitochondrial biogenesis and respiration through the thermogenic coactivator PGC-1. Cell. 1999; 1: 115-124.

23. Gruzman A, Babai G, Sasson S. Adenosine Monophosphate-Activated Protein Kinase (AMPK) as a New Target for Antidiabetic Drugs: A Review on Metabolic, Pharmacological and Chemical Considerations. Rev Diabet Stud. 2009; 1: 13-36.

24. Ruderman N, Prentki M. AMP kinase and malonylCoA: targets for therapy of the metabolic syndrome. Nat Rev Drug Discov. 2004; 4: 340-351.

25. An J, Muoio DM, Shiota M, Fujimoto Y, Cline GW, Shulman GI, Koves TR, Stevens R, Millington D, Newgard CB. Hepatic expression of malonyl-CoA decarboxylase reverses muscle, liver and wholeanimal insulin resistance. Nat Med. 2004; 3: 268274.

26. Clapham DE. Calcium signaling. Cell. 2007; 6: 1047-1058.

27. Berridge MJ, Bootman MD, Roderick HL. Calcium signalling: dynamics, homeostasis and remodelling. Nat Rev Mol Cell Biol. 2003; 7: 517-529.

28. Dedov VN, Tran VH, Duke CC, Connor M, Christie MJ, Mandadi S, Roufogalis BD. Gingerols: a novel class of vanilloid receptor (VR1) agonists. Br J Pharmacol. 2002; 6: 793-798.

29. Chen CY, Chen CH, Kung CH, Kuo SH, Kuo SY. [6]-gingerol induces $\mathrm{Ca} 2+$ mobilization in MadinDarby canine kidney cells. J Nat Prod. 2008; 1: 137-140.

30. Foley K, Boguslavsky S, Klip A. Endocytosis, recycling, and regulated exocytosis of glucose transporter 4. Biochemistry. 2011; 15: 3048-3061.
31. Lopez JA, Burchfield JG, Blair DH, Mele K, Ng Y, Vallotton P, James DE, Hughes WE. Identification of a distal GLUT4 trafficking event controlled by actin polymerization. Mol Biol Cell. 2009; 17: 3918-3929.

32. Furuta A, Tanaka M, Omata W, Nagasawa M, Kojima I, Shibata H. Microtubule disruption with BAPTA and dimethyl BAPTA by a calcium chelation-independent mechanism in 3T3-L1 adipocytes. Endocr J. 2009; 2: 235-243.

33. Worrall DS, Olefsky JM. The effects of intracellular calcium depletion on insulin signaling in 3T3-L1 adipocytes. Mol Endocrinol. 2002; 2: 378-389.

34. Whitehead JP, Molero JC, Clark S, Martin S, Meneilly G, James DE. The role of $\mathrm{Ca} 2+$ in insulinstimulated glucose transport in 3T3-L1 cells. J Biol Chem. 2001; 30: 27816-27824.

35. Verhoeven AJ, Woods A, Brennan CH, Hawley SA, Hardie DG, Scott J, Beri RK, Carling D. The AMPactivated protein kinase gene is highly expressed in rat skeletal muscle. Alternative splicing and tissue distribution of the mRNA. Eur J Biochem. 1995; 2: 236-243.

36. Woods A, Salt I, Scott J, Hardie DG, Carling D. The alpha1 and alpha2 isoforms of the AMPactivated protein kinase have similar activities in rat liver but exhibit differences in substrate specificity in vitro. FEBS Lett. 1996; 2-3: 347-351.

37. Salt I, Celler JW, Hawley SA, Prescott A, Woods A, Carling D, Hardie DG. AMP-activated protein kinase: greater AMP dependence, and preferential nuclear localization, of complexes containing the alpha2 isoform. Biochem J. 1998; 177-187.

38. Viollet B, Andreelli F, Jorgensen SB, Perrin C, Geloen A, Flamez D, Mu J, Lenzner C, Baud O, Bennoun M, Gomas E, Nicolas G, Wojtaszewski JF, Kahn A, Carling D, Schuit FC, Birnbaum MJ, Richter EA, Burcelin R, Vaulont S. The AMPactivated protein kinase alpha2 catalytic subunit controls whole-body insulin sensitivity. J Clin Invest. 2003; 1: 91-98.

39. Jorgensen SB, Viollet B, Andreelli F, Frosig C, Birk JB, Schjerling P, Vaulont S, Richter EA, Wojtaszewski JF. Knockout of the alpha2 but not alpha1 5'-AMP-activated protein kinase isoform abolishes 5-aminoimidazole-4-carboxamide-1beta-4-ribofuranosidebut not contraction-induced glucose uptake in skeletal muscle. J Biol Chem. 2004; 2: 1070-1079.

40. Bruce CR, Mertz VA, Heigenhauser GJ, Dyck DJ. The stimulatory effect of globular adiponectin on insulin-stimulated glucose uptake and fatty acid oxidation is impaired in skeletal muscle from obese subjects. Diabetes. 2005; 11: 3154-3160.

41. Egawa T, Hamada T, Ma X, Karaike K, Kameda N, Masuda S, Iwanaka N, Hayashi T. Caffeine activates preferentially alpha1-isoform of 5'AMPactivated protein kinase in rat skeletal muscle. Acta Physiol (Oxf). 2011; 2: 227-238. 